\title{
Endocytosis of Particle Formulations by Macrophages and Its Application to Clinical Treatment
}

\author{
Keiji Hirota and Hiroshi Terada
}

Additional information is available at the end of the chapter

http://dx.doi.org/10.5772/45820

\section{Introduction}

Macrophages are known to take up "invaders" such as pathogens and viruses mainly by phagocytosis to protect the host from infections by them. This process of phagocytosis is disadvantageous in general for exhibition of an efficient pharmacological effect of particle formulations containing drugs, because the uptake of particles by macrophages reduces the extracellular drug concentration. Hence, it is important to understand what properties of particles are advantageous or disadvantageous for phagocytic uptake by macrophages. Modification of particles by polyethylene glycol (PEG), which forms a hydrated phase on the surface of particles, enables long-lasting circulation of such particles in the bloodstream by circumventing their uptake by macrophage cells [1].

In contrast, particle formulations that are easily taken up by macrophages would be highly advantageous for macrophage-targeting drug delivery [2]. In this case, a typical example is the treatment of tuberculosis (TB). Namely, Mycobacterium tuberculosis (MTB) cells are easily trapped in the phagosomes of alveolar macrophages. However, these cells are not digested by macrophages, because the fusion of the MTB-containing phagosomes with lysosomes, which are indispensable for the digestion of bacteria inside phagosomes, is inhibited. As a result, MTB cells proliferate and accumulate inside macrophages [3]. Hence, the delivery of particles containing antituberculosis agents to alveolar macrophages would be expected to be effective for TB therapy.

As summarized in Figure 1, endocytic uptake including phagocytosis is classified according to the mechanism of vesicle formation as well as the size of particles ingested [4-7]. Phagocytosis is performed by specialized cells such as macrophages, and it plays a role in the clearance of particles having a diameter greater than $0.5 \mu \mathrm{m}$. On the other hand, 
pinocytosis occurs in all cells, including macrophages and cancer cells, for obtaining nutrients and biological mediators. It is noteworthy that macropinocytosis covers a broad range of particle sizes from $100 \mathrm{~nm}$ to $5 \mu \mathrm{m}$ [8-10].

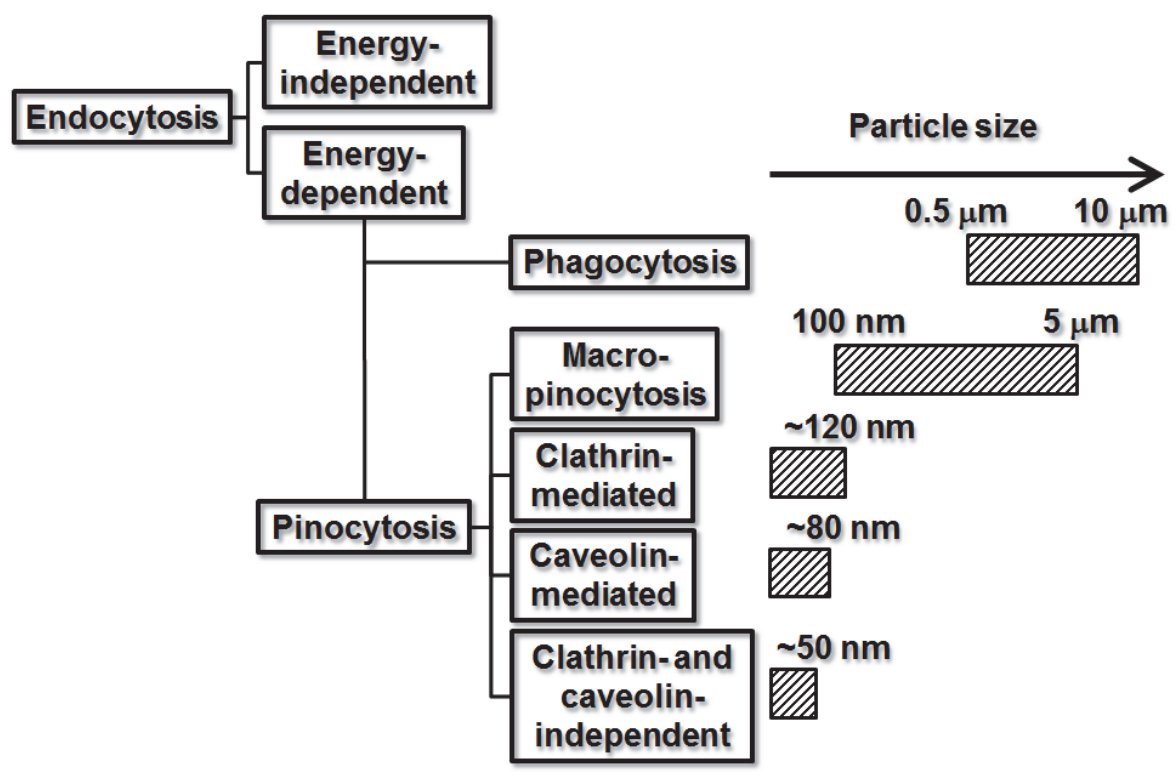

Figure 1. Classification of endocytosis in relation to particle sizes favorable for ingestion.

In this chapter, features of phagocytosis of particles in terms of particle properties, as well as phagocytosis-induced physiological events of macrophages, are described. In addition, the promising aspect of clinical treatment by the utilization of endocytosis-mediated drug action is reviewed.

\section{Effect of particle properties on endocytosis}

Drug-containing particle formulations are commonly used for delivery of drugs. The particle base is the most important part of a formulation. Poly (lactic-glycolic) acid (PLGA) is one of the candidates for drug-containing particle formulations, because PLGA is biodegradable and biocompatible [11]. Drug release from the particles and its sustainability can be regulated by changing the molecular weight and composition of the lactate and glycolate moieties of PLGA [12].

Phagocytic uptake of particles by macrophage cells proceeds as follows: 1) access of particles to the surface of the macrophage membrane, 2) particle recognition by phagocytic receptors on the macrophage membrane, and 3) dynamic changes in membrane structure (protrusion or invagination). Particle size, shape, and surface properties affect efficient entrapment and subsequent uptake by macrophages. 


\subsection{Particle size}

Particle size is likely the primary factor that governs endocytic uptake of particles. The optimum size of particles for efficient endocytic uptake varies according to the cell type. Macrophage cells are able to ingest large particles having a diameter between $1 \mu \mathrm{m}$ and 10 $\mu \mathrm{m}$ to eliminate invaders from outside the body $[13,14]$. The optimal sizes of the particles for the uptake by alveolar macrophages range between $3 \mu \mathrm{m}$ and $6 \mu \mathrm{m}$ [15], but those by peritoneal macrophages and peripheral blood mononuclear cells are reportedly from $0.3 \mu \mathrm{m}$ to $1.1 \mu \mathrm{m}$ [16-18]. The uptake mechanism of the particles, such as $3-\mu \mathrm{m}$ particles, was interpreted by the Derjaguin-Landau-Verwey-Overbeek (DLVO) theory [19].

Nanoparticles are advantageous for attacking carcinoma cells, which mainly originate from epithelial cells. The optimal size of the particles for the uptake by carcinoma cells was reported to be around $50 \mathrm{~nm}$, as determined by the use of gold nanoparticles [20]. Besides micrometersize particles, macrophages also take up nano-size particles [21]. The uptake of nano-size particles mainly proceeds via pinocytosis in such a way that the rate of pinocytosis is dependent on the extracellular particle concentration and time of exposure. For ingestion of liquid phase, this rate for mouse fibroblast $\mathrm{L}$ cells is $18.7 \mu \mathrm{m}^{3} / \mathrm{hr} /$ cell, which value is less than that for mouse resident peritoneal macrophages, $46.5 \mu \mathrm{m}^{3} / \mathrm{hr} / \mathrm{cell}$ [22,23]. Hence, understanding of particle properties other than size is also important for particle delivery.

\subsection{Shape}

Particle shape is another major factor affecting endocytic uptake by macrophages. The macrophage membrane undergoes structural changes in such a way that the membrane spreads around the particle, starting from the initial contact site between particle and membrane; and the progression of endocytic uptake of particles is dependent on the contact angle between particle and macrophage membrane. For example, an elliptical disk-shaped particle is internalized along its long axis when the particle has attached perpendicularly to the cell membrane, in which case the contact angle is small [24]. In this case, the membrane spreads symmetrically around the particle, engulfing it. In contrast, attachment when the short axis is perpendicular to the membrane increases the angle of contact and the number of contact points with the membrane, which then starts to spread asymmetrically. As a result, the particle is not engulfed. However, when the long axis of particles ranges from 2-3 $\mu \mathrm{m}$, which corresponds to that of most bacteria, maximum attachment to macrophage cells occurs; and engulfment is successful even though the angle of contact is large [25].

\subsection{Surface properties}

Most mammalian cells including macrophage cells have negative charges on their surface $[26,27]$. As the loss of the negative surface charge of the membrane is thought to influence protein localization during endocytosis [28], the surface charge of particles is thought to be also critical for endocytic uptake. In fact, it is reported that changes in cellulose particles by the introduction of extremely negatively charged sulphoethyl residues or of positively charged diethylaminoethyl groups affect the endocytic uptake by mouse peritoneal macrophage cells 
and that the endocytic uptake is the lowest for particles without having surface charge, as determined in terms of zeta potential [29].

Charge density is also important. The Ohshima theory, based on the analysis of the membrane surface in terms of electrophoretic "softness" and the density of the fixed charge [30], will be effective for understanding of the interaction of particles with cell membranes [31]. Polystyrene particles having electrophoretic softness and a low negative electrical charge density by the introduction of primary amine and carboxyl groups on their surface were reported to be more susceptible to endocytic uptake by rat alveolar macrophage cells than those having more rigid and higher electrical charge density by the introduction of hydroxyl and sulfate groups [13].

\subsection{Particle formulations}

Particle formulations affect directly the interaction of particles with the endocytic receptors of macrophage cells. The exposure of the phosphatidylserine moiety on the membrane of apoptotic lymphocytes is important for their removal by endocytosis by macrophage cells through recognition via scavenger receptors on the macrophages [32]. Based on this mechanism, liposomes containing phosphatidylserine are more susceptible to uptake by macrophage-like HL-60RG cells than those containing phosphatidylethanolamine or phosphatidic acid [33].

PLGA has been commonly used as a base of particle formulations. Macrophage cells eat PLGA particles more efficiently than polystyrene latex ones. It is noteworthy that phagocytosis of PLGA particles by alveolar macrophage cells stimulates their phagocytic activity in such a way that their uptake increases both the population of phagocytic macrophage cells and the number of particles that have been taken up by individual macrophage [34]. However, the mechanism of interaction of PLGA with macrophage cells is still unknown.

\section{Induction of inflammatory responses by endocytosis}

Macrophage cells patrol around the tissue where they reside and play a central role in the clearance of invaders. The total surface area of human alveoli is approx. $70 \mathrm{~m}^{2}$, where 23 billion alveolar macrophage cells reside [35,36]. Namely, a single macrophage cell should monitor invaders in an area of a square with a side length of $55 \mu \mathrm{m}$. When macrophage cells encounter invaders, the cells eliminate them by phagocytosis and subsequent digestion with lysosomal enzymes. Simultaneously, macrophage cells generate inflammatory mediators, working as signals to inform the surrounding cells that invaders are coming. Macrophage cells also recognize drug carrier particles as invaders, and then, "undesirable" immune responses such as the production of antibody and inflammatory mediators take place. Hence, silent nature toward macrophage cell functions is required for efficient drug carrier particles.

In the case of endocytosis-mediated drug action (see section 5), high particle uptake by macrophages is favorable. Such efficient uptake will be achieved by up-regulation of endocytic activity, but this action may trigger undesirable immune responses from macrophages. If 
efficient particle uptake is not associated with the induction of the undesirable responses, the particles could be very useful as drug carriers. As summarized in Table 1, PLGA particles are those having such a desirable silent nature regarding inflammatory responses, although they are yet well phagocytosed by macrophages compared with polystyrene latex (PSL) particles [34,37]. Namely, the PLGA particle behaves like a "Ninja," having stealth and concealment activities. However, it is still unknown how particle formulation and modification are relevant to this silent nature. In this section, we review two distinct pathways involved in signal transduction to generate inflammatory mediators, one using phagocytic receptors and the other, pattern recognition receptors (PRRs).

\begin{tabular}{lccc}
\hline \multicolumn{1}{r}{ Responses } & \multicolumn{3}{c}{ Particles } \\
& PLGA & PSL & LPS \\
\hline Cell death & - & + & ++ \\
TNF- $\alpha$ & - & + & ++ \\
NO & - & + & ++ \\
IL-10 & - & - & + \\
TGF- $\beta$ & - & + & - \\
Phagostimulation & + & - & \pm \\
\hline
\end{tabular}

These data are summarized from reports [34,37]. Rat alveolar macrophage cells (NR8383)

were exposed to PLGA and PSL particles at a number 10 times greater than the cell number. LPS existing in micellar form in the incubation medium was used at the concentration of $1 \mu \mathrm{g} / \mathrm{mL}$ as a reference. $(-)$, no responses; $(+)$, mild responses; (++), significantly high response than (+).

Table 1. Alveolar macrophage cellular responses induced by particle uptake.

\subsection{Phagocytosis-mediated inflammatory response}

Phagocytic cells, such as macrophages, monocytes, and polymorphonuclear cells, take up particles and pathogens typically with sizes of more than $0.5 \mu \mathrm{m}$ to clear them from the body mainly by phagocytosis $[4,38]$. In the case of macrophages, the ingestion of particles proceeds in such a way that the interaction of the particles with phagocytic receptors causes extension of pseudopods from the plasma membrane to capture the particles, which action is followed by engulfment by these phagocytes [5]. This phagocytic mechanism, called the "zipper" model, requires a reorganization of the actin-based cytoskeleton underlying the region of plasma membrane in contact with the particles and induces signal transduction through the Fc $\gamma$ receptor (Fc $\gamma R$ ) and complement-receptor 3 (CR3) [39].

The cross-linking of the $\mathrm{Fc} \gamma \mathrm{R}$ by particles simultaneously initiates a series of signal transduction events mediated by multiple protein tyrosine kinases, phosphoinositide, and free arachidonic acid [40-42]. In the case of monocytes, the cross-linking of Fc $\gamma \mathrm{R}$ by $\operatorname{IgG}$ initiates the release of TNF- $\alpha$, IL-1 $\beta$, IL-6, IL-8, and monocyte chemoattractant protein-1 (MCP-1), which molecules are classified as T helper 1 ( $\left.\mathrm{T}_{\mathrm{H}} 1\right)$ cytokines [43-47]. Macrophage cells are also stimulated by the cross-linking of Fc $\gamma$ R by IgG; and these cells generate TNF- $\alpha$ 
through MAPK signal transduction, leading to NF- $\mathrm{BB}$ activation $[48,49]$. In the presence of IL-3 and a high density of IgG, IL-4 and IL-10 of the $\mathrm{T}_{\mathrm{H}} 2$ inflammatory cytokine family are synthesized in macrophage cells by the cross-linking via IgG [50,51]. Signal transduction initiated from Fc $\gamma$ Rs is involved in inflammatory immune responses.

In contrast, CR3-mediated phagocytosis by macrophages, which is cooperative with FcyRmediated phagocytosis [52], seems to be involved in anti-inflammatory responses rather than in inflammatory responses, though various signal transductions mediated by tyrosine kinase are initiated from CR3 [53]. Generation of IL-12 in human monocytes is known to be stimulated by phagocytosis of Staphylococcus aureus. However, treatment of the phagocytic monocytes with $\mathrm{iC} 3 \mathrm{~b}$, the natural CR3 ligand, down-regulates the generation of IL-12, suggesting that CR3 suppresses the inflammatory response [54]. In addition, ligation of CR3 suppresses the release of $T_{H} 1$ cytokines, such as TNF- $\alpha$, IL- 6 and IL-12, and the $T_{H} 2$ cytokine IL-10 from LPS-stimulated bone marrow-derived mouse dendritic cells [55]. Hence, it is possible that CR3 is associated with the silent nature of the entry of particles, such as PLGA particles, into phagocytic cells.

\subsection{Pattern recognition-mediated inflammatory responses}

There are macrophage cells in various vertebrates and invertebrates that are capable of recognizing highly conserved pathogenic molecular patterns by receptors called pattern recognition receptors (PRRs) [56,57]. These receptors are classified into two major groups, one involved in endocytic uptake, such as scavenger receptors (SRs), and the other associated with transmission of danger signals independent of endocytosis, such as Toll-like receptors (TLRs) and nucleotide-binding domain leucine-rich repeat-containing receptors (NLRs) $[57,58]$. It is of importance to understand signal transduction from these receptors for construction of silent drug delivery using particles.

Lipopolysaccharide (LPS) micelles and silica particles are reported to bind with SRs, which binding is followed by their engulfment by macrophages [59-61]. In sepsis patients, SRs play a role in efficient clearance of LPS and attenuation of LPS-induced inflammatory responses [62]. However, signaling pathways initiated from SRs are difficult to identify, because ligands of SRs, such as LPS and polyinosinic acid, simultaneously stimulate TLRs as well. Overexpression of class B SRs in human epithelial carcinoma HeLa cells and human embryonic kidney cells (HEK293) increases the production of the inflammatory mediator IL8 associated with increased uptake of LPS [63]. This inflammatory response seems to be due to interaction of SRs with LPS. In contrast, CD163, a hemoglobin scavenger receptor, downregulates $\mathrm{T}_{\mathrm{H}} 1$ inflammatory responses by initiation of signaling leading to secretion of $\mathrm{T}_{\mathrm{H}} 2$ cytokines [64]. SRs are associated with TLR-independent signaling pathways and involved in inflammatory responses similarly as Fc $\gamma$ R.

TLRs play an important role in innate immunity and recognize various molecules derived from bacteria and viruses [65]. TLR3 and TLR7 express on the endosomal membrane and work as sensors for elimination of unnecessary nucleic acids by induction of 
inflammatory responses; and these responses should be taken into account for delivery of nucleic acids, such as small interfering RNA (siRNA). Administration of siRNA via liposomes or transgenic reagent Lipofectamine ${ }^{\circledR}$ induce potent immunostimulation generating $\mathrm{T}_{\mathrm{H}} 1$ inflammatory cytokines from human monocytes and plasmacytoid dendritic cells [66,67]. In addition, immune responses through TLRs' signals cause adoptive immunity, such as the generation of antibody [68]. It is of importance to study the mechanism of signal transduction associated with TLRs for understanding of the generation of undesirable immune responses. To overcome these problems, nanoparticles will be effective, because they are able to escape from endosomes into the cytosol, where these nanoparticles release drugs. Based on this strategy, delivery of siRNA-containing nanoparticles into HeLa cells and human pancreatic carcinoma PanC-1 cells is reported to be successful $[69,70]$.

The role of NLRs should also be taken into consideration in the delivery of particles. One of the most characterized NLRs is NLRP3 (also known as NALP3 or cryopyrin) [71]. It is noteworthy that the inflammasome (NLRP3), which contains procaspase-1, senses lysosomal enzymes in the cytosol, leading to the activation of caspase- 1 and that this event is followed by secretion of the inflammatory mediators IL-1 $\beta$, IL-18, and IL-33 $[58,72]$. Uptake of micro-particles of silica crystals and aluminum hydroxide causes leakage of the lysosomal enzyme cathepsin B into the cytosol due to destabilization of the lysosomal membrane in human and mouse macrophage cells [73,74]. Possibly, NLRs work as a sensor of danger signals initiated from lysosomal destabilization caused by uptake of such micro-particles. It should be important to know the effect of undegradable particles on the stability of lysosomes for understanding of the onset of cytotoxicity by phagocytosis of particles.

\section{Lipid-raft-dependent uptake of particles}

When particles are caught by macrophage cells, the macrophage membrane undergoes structural changes after recognition of the particles by endocytic receptors located in the membrane region. This membrane region, referred to as a lipid raft, is enriched in sphingolipids and cholesterol, which serve as a scaffold for the proper functioning of endocytic receptors and various signal transduction pathways [75,76]. In microglia, signaling cascades triggered in response to gangliosides are mediated by recruitment of Src homology 2 domain-containing protein-tyrosine phosphatase 2 (SHP-2) to lipid rafts [77].

Caveolae, a subset of lipid rafts, control various biological events including endocytosis [78] and are associated with the incorporation of pathogens [79]. There is another possibility that inclusion of protein receptors in the rafts is closely associated with phagocytic uptake of particles, because CD36, a class B SR, exists in caveolin-containing lipid rafts in human melanoma cells [80]. A cyclodextrin, $\mathrm{M} \beta \mathrm{CD}$ is commonly used as a reagent to disrupt lipid rafts by the extraction of cholesterol [81]. Treatment of mouse macrophage-like J774 cells 
with $\mathrm{M} \beta \mathrm{CD}$ inhibits recruitment of SRs to lipid raft domain [82]. As a result, phagocytic activity toward PSL particles, which are ingested through SRs, decreases. Similarly, recruitment of CD36 to raft domains is necessary for phagocytosis of amyloid $\beta$ by microglial cells [83]. Lipid rafts are essential for recruitment of phagocytic receptors; and, hence, they are associated with delivery of drug-containing particles by phagocytosis.

An alternative function of lipid rafts is to provide a scaffold for TLRs associated with danger signal transduction. Stimulation of human peripheral blood monocytes with LPS causes clustering of the signaling receptor TLR4 with its accessory protein CD14 [84], and association of this receptor cluster with lipid rafts is thought to be necessary for LPSinduced signal transduction [85]. An increase in membrane fluidity due to ethanol at a concentration of higher than $50 \mathrm{mM}$ inhibits the association of TLR4 with lipid rafts, suppressing LPS-induced TNF- $\alpha$ production in mouse macrophage cells [86]. However, it is interesting to note that treatment with $\mathrm{M} \beta \mathrm{CD}$ does not affect LPS-induced gene expression relating to inflammation [87]. This could be because MyD88, the adaptor protein of TLR4, exists in a membrane region other than lipid rafts [88]. In addition, generation of nitric oxide from macrophage cells after disruption of lipid rafts by MBCD is comparable to that of intact macrophage cells, though the $\mathrm{M} \beta \mathrm{CD}$ treatment decreases phagocytic activity toward the PSL particles by a half [87]. Further studies on the operation of inflammatory signaling cascades in relation with lipid rafts are needed.

\section{Endocytosis-mediated drug action}

In the lungs, macrophage cells patrol the air/cell interfaces and play a role in protecting the host from invaders such as pathogens and viruses by phagocytic uptake. However, some pathogens, such as MTB, survive in macrophage cells and proliferate well by using them as incubators after the pathogens have been inhaled into the alveoli by respiration [3]. Owing to this survival strategy, MTB is able to escape from the attack of antitubercular agents, and this is one of the reasons why effective treatment of TB has not been successful till now.

As macrophages phagocytose particle formulations besides bacteria and viruses, utilization of this phagocytosis-mediated transport of these drug formulations into MTB-infected macrophages is expected to be promising for therapy of TB. For this approach, particles containing an antitubercular agent are delivered to the lungs, where alveolar macrophages infected with MTB reside. The macrophages take up the particles, and the antitubercular agent thus phagocytosed in a form of particles attacks the MTB. The effect of PLGA microspheres containing rifampicin (RFP), one of the first-line drugs for TB treatment, on MTB has been well examined to date $[89,90]$. PLGA microspheres containing RFP (RFPPLGA) were prepared by various methods such as double-emulsification and spray-drying. The PLGA MS thus prepared deliver an amount of RFP into rat alveolar macrophage NR8383 cells in vitro about 20 times greater than that added in the free form in solution $[12,37]$. Inhalation of PLGA MS containing the antitubercular agent rifabutin increases the drug residence time in the lungs to more than that by intravenous administration in mice due to uptake of the particles by alveolar phagocytic cells [91]. However, the bacterial 
population in the rat lung is not significantly decreased by pulmonary administration of RFP-PLGA MS, though granuloma formation on the surface of the lung is reduced [92].

To achieve efficient phagocytosis-mediated TB treatment, at least three requirements must be met. Namely, drug-containing particles should be 1) well phagocytosed by alveolar macrophages, 2) exhibit a potent bactericidal effect on MTB inside the macrophages, and 3) should not be toxic to the phagocytes. PLGA particles containing an antitubercular agent well satisfy these three requirements. In addition, homogeneous distribution of drugcontaining particles in the target tissue is required to obtain the optimum effect. Understanding of endocytic activities of MTB-infected macrophages toward drugcontaining particles in vivo is thus important for improving TB therapy.

Another promising aspect of endocytosis-mediated therapy could be the treatment of cancer. One possible way would be the induction of inflammatory mediators, such as NO and TNF- $\alpha$, in macrophages by immunomodulators such as TLR-ligands, leading to their cytotoxic effects on tumor cells [93-95]. In addition, "re-education" of the healing-type macrophages (M2 macrophages) to the killer-type macrophages (M1 macrophages) by immunomodulators should be effective as well [96]. An increase in the M1 macrophage population could be advantageous for the treatment of tumors. As TLRs are expressed on various cell membranes in the body, endocytosis-mediated delivery of TLR-ligands to macrophage cells should be effective in overcoming malignant neoplasms without the induction of undesirable immune responses.

\section{Conclusions}

The physiological function of macrophage cells is important in overcoming various diseases, because they rid the body of pathogens by phagocytosis. Hence, phagocytosis-mediated drug delivery is useful for a direct attack against pathogenic bacteria and viruses residing inside macrophage cells. As summarized in Figure 2, the optimum properties of particles targeting macrophage cells are a) "macrophage-philicity," especially toward phagocytic receptors and lipid rafts, b) ability to stimulate actin reorganization, c) a silent nature like a "Ninja" with respect to inflammatory responses, and d) ability to allow rapid release of the incorporated drugs. Of these, items " $a$ " and " $b$ " refer to the feasibility of particles for their efficient ingestion; and spherical particles having about 3- $\mu$ m diameter and surface charges are likely to be favorable for phagocytic uptake. Item " $c$ " is associated with a nontoxic effect on macrophage function; and item " $\mathrm{d}$ " is important for exhibition of drug action, in which the release of drugs from the particles modulates the drug action.

In addition, activation of the macrophages of the immune system is advantageous for attack against pathological cells residing close to macrophages, such as tumor cells. It is noteworthy that certain bases, such as PLGA, of the particles themselves modulate the immune functions of macrophages. Development of drug-containing particles, which efficiently attack the pathogens or pathological cells, and which upregulate the immunological function of macrophages, is beneficial to overcome infectious diseases and cancer. 


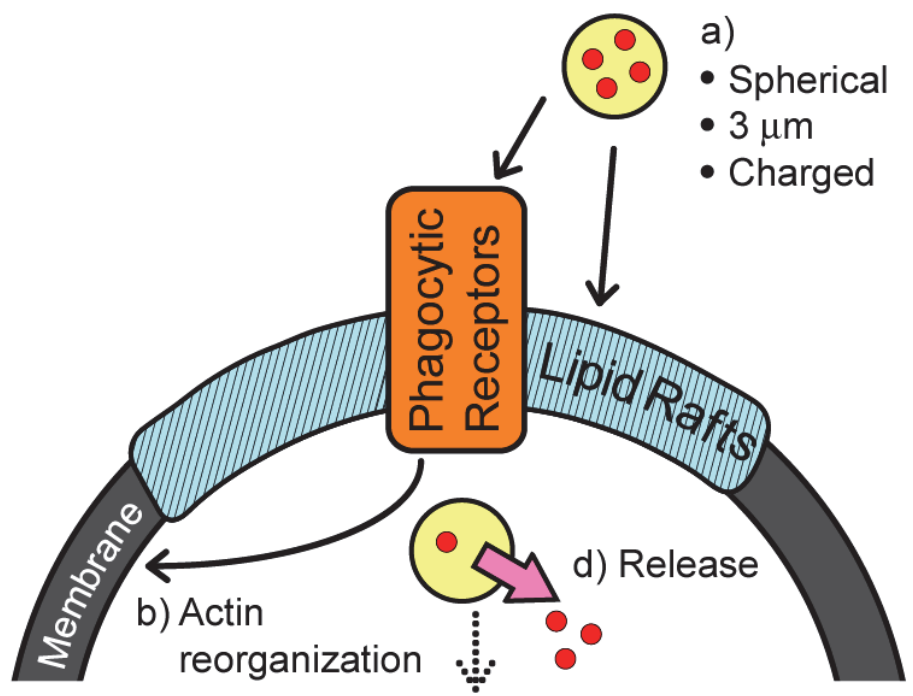

c) Silent

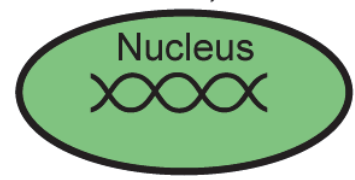

Figure 2. Biochemical events associated with endocytosis-mediated drug delivery via particles.

\section{Author details}

Keiji Hirota and Hiroshi Terada

Faculty of Pharmaceutical Sciences, Japan

Center for Drug Delivery Research, Japan

Center for Physical Pharmaceutics, Research Institute for Science and Technology, Tokyo University of Science, Yamazaki, Noda, Chiba, Japan

\section{Acknowledgement}

This work was supported, in part, by the program for development of strategic research center in private universities supported by MEXT (Ministry for Education, Culture, Sports, Science, and Technology) of Japan, 2010-2014.

\section{References}

[1] Gabizon, A.A., Barenholz, Y., and Bialer, M. (1993). Prolongation of the circulation time of doxorubicin encapsulated in liposomes containing a polyethylene glycol-derivatized phospholipid: pharmacokinetic studies in rodents and dogs. Pharm Res 10, 703-708. 
[2] Gordon, S., and Rabinowitz, S. (1989). Macrophages as targets for drug delivery. Adv Drug Deliv Rev 4, 27-47.

[3] Armstrong, J.A., and Hart, P.D. (1975). Phagosome-lysosome interactions in cultured macrophages infected with virulent tubercle bacilli. Reversal of the usual nonfusion pattern and observations on bacterial survival. J Exp Med 142, 1-16.

[4] Aderem, A., and Underhill, D.M. (1999). Mechanisms of phagocytosis in macrophages. Annu Rev Immunol 17, 593-623.

[5] Conner, S.D., and Schmid, S.L. (2003). Regulated portals of entry into the cell. Nature 422, 37-44.

[6] Hansen, C.G., and Nichols, B.J. (2009). Molecular mechanisms of clathrin-independent endocytosis. J Cell Sci 122, 1713-1721.

[7] Sahay, G., Alakhova, D.Y., and Kabanov, A.V. (2010). Endocytosis of nanomedicines. J Control Release 145, 182-195.

[8] Swanson, J.A., and Watts, C. (1995). Macropinocytosis. Trends Cell Biol 5, 424-428.

[9] Tamaru, M., Akita, H., Fujiwara, T., Kajimoto, K., and Harashima, H. (2010). Leptinderived peptide, a targeting ligand for mouse brain-derived endothelial cells via macropinocytosis. Biochem Biophys Res Commun 394, 587-592.

[10] Bhattacharya, S., Roxbury, D., Gong, X., Mukhopadhyay, D., and Jagota, A. (2012). DNA conjugated SWCNTs enter endothelial cells via Rac1 mediated macropinocytosis. Nano Lett.

[11] Gilding, D.K., and Reed, A.M. (1979). Biodegradable polymers for use in surgery Polyglycolic-Poly(Actic Acid) homopolymers and copolymers .1. Polymer 20, 1459-1464.

[12] Makino, K., Nakajima, T., Shikamura, M., Ito, F., Ando, S., Kochi, C., Inagawa, H., Soma, G.-I., and Terada, H. (2004). Efficient intracellular delivery of rifampicin to alveolar macrophages using rifampicin-loaded PLGA microspheres: effects of molecular weight and composition of PLGA on release of rifampicin. Colloid and Surf B: Biointerfaces 36, 35-42.

[13] Makino, K., Yamamoto, N., Higuchi, K., Harada, N., Ohshima, H., and Terada, H. (2003a). Phagocytic uptake of polystyrene microspheres by alveolar macrophages: effects of the size and surface properties of the microspheres. Colloid Surf B: Biointerfaces 27, 33-39.

[14] Hasegawa, T., Hirota, K., Tomoda, K., Ito, F., Inagawa, H., Kochi, C., Soma, G., Makino, K., and Terada, H. (2007). Phagocytic activity of alveolar macrophages toward polystyrene latex microspheres and PLGA microspheres loaded with anti-tuberculosis agent. Colloid Surf B: Biointerfaces 60, 221-228.

[15] Hirota, K., Hasegawa, T., Hinata, H., Ito, F., Inagawa, H., Kochi, C., Soma, G., Makino, K., and Terada, H. (2007). Optimum conditions for efficient phagocytosis of rifampicinloaded PLGA microspheres by alveolar macrophages. J Control Release 119, 69-76.

[16] Pratten, M.K., and Lloyd, J.B. (1986). Pinocytosis and phagocytosis: the effect of size of a particulate substrate on its mode of capture by rat peritoneal macrophages cultured in vitro. Biochim Biophys Acta 881, 307-313.

[17] Seymour, L., Schacht, E., and Duncan, R. (1991). The effect of size of polystyrene particles on their retention within the rat peritoneal compartment, and on their interaction with rat peritoneal macrophages in vitro. Cell Biol Int Rep 15, 277-286. 
[18] Kawaguchi, H., Koiwai, N., Ohtsuka, Y., Miyamoto, M., and Sasakawa, S. (1986). Phagocytosis of latex particles by leucocytes. I. Dependence of phagocytosis on the size and surface potential of particles. Biomaterials 7, 61-66.

[19] Champion, J.A., Walker, A., and Mitragotri, S. (2008). Role of particle size in phagocytosis of polymeric microspheres. Pharm Res 25, 1815-1821.

[20] Chithrani, B.D., Ghazani, A.A., and Chan, W.C. (2006). Determining the size and shape dependence of gold nanoparticle uptake into mammalian cells. Nano Lett 6, 662-668.

[21] He, C., Hu, Y., Yin, L., Tang, C., and Yin, C. (2010). Effects of particle size and surface charge on cellular uptake and biodistribution of polymeric nanoparticles. Biomaterials 31, 3657-3666.

[22] Steinman, R.M., Silver, J.M., and Cohn, Z.A. (1974). Pinocytosis in fibroblasts. Quantitative studies in vitro. J Cell Biol 63, 949-969.

[23] Edelson, P.J., Zwiebel, R., and Cohn, Z.A. (1975). The pinocytic rate of activated macrophages. J Exp Med 142, 1150-1164.

[24] Champion, J.A., and Mitragotri, S. (2006). Role of target geometry in phagocytosis. Proc Natl Acad Sci U S A 103, 4930-4934.

[25] Doshi, N., and Mitragotri, S. (2010). Macrophages recognize size and shape of their targets. PLoS One 5, e10051.

[26] Weiss, L. (1969). The cell periphery. Int Rev Cytol 26, 63-105.

[27] Mutsaers, S.E., and Papadimitriou, J.M. (1988). Surface charge of macrophages and their interaction with charged particles. J Leukoc Biol 44, 17-26.

[28] Yeung, T., Terebiznik, M., Yu, L., Silvius, J., Abidi, W.M., Philips, M., Levine, T., Kapus, A., and Grinstein, S. (2006). Receptor activation alters inner surface potential during phagocytosis. Science 313, 347-351.

[29] Tabata, Y., and Ikada, Y. (1988). Effect of the size and surface charge of polymer microspheres on their phagocytosis by macrophage. Biomaterials 9, 356-362.

[30] Ohshima, H. (1994). Electrophoretic Mobility of Soft Particles. J Colloid Interface Sci 163, 474-483.

[31] Makino, K., Fukai, F., Hirata, S., and Ohshima, H. (1996). Electro-osmotic studies of endothelial cell surface. Colloid Surf B: Biointerfaces 7, 235-238.

[32] Fadok, V.A., Voelker, D.R., Campbell, P.A., Cohen, J.J., Bratton, D.L., and Henson, P.M. (1992). Exposure of phosphatidylserine on the surface of apoptotic lymphocytes triggers specific recognition and removal by macrophages. J Immunol 148, 2207-2216.

[33] Makino, K., Tabata, J., Yoshioka, T., Fukuda, M., Ikekita, M., Ohshima, H., and Terada, H. (2003b). Effects of liposomal phosphatidylserine on phagocytic uptake of liposomes by macrophage-like HL-60RG cells. Colloid Surf B: Biointerfaces 29, 277-284.

[34] Hirota, K., Hasegawa, T., Nakajima, T., Makino, K., and Terada, H. (2011). Phagostimulatory effect of uptake of PLGA microspheres loaded with rifampicin on alveolar macrophages. Colloid Surf B: Biointerfaces 87, 293-298.

[35] Weibel, E.R. (1963). Geometry and dimensions of airways of respiratory zone. In: Morphometry of the human lung. Heidelberg: Springer-Verlag.

[36] Crapo, J.D., Barry, B.E., Gehr, P., Bachofen, M., and Weibel, E.R. (1982). Cell number and cell characteristics of the normal human lung. Am Rev Respir Dis 126, 332-337. 
[37] Hirota, K., Hasegawa, T., Nakajima, T., Inagawa, H., Kohchi, C., Soma, G., Makino, K., and Terada, H. (2010a). Delivery of rifampicin-PLGA microspheres into alveolar macrophages is promising for treatment of tuberculosis. J Control Release 142, 339-346.

[38] Rabinovitch, M. (1995). Professional and non-professional phagocytes: an introduction. Trends Cell Biol 5, 85-87.

[39] Swanson, J.A., and Baer, S.C. (1995). Phagocytosis by zippers and triggers. Trends Cell Biol 5, 89-93.

[40] Greenberg, S., Chang, P., and Silverstein, S.C. (1993). Tyrosine phosphorylation is required for Fc receptor-mediated phagocytosis in mouse macrophages. J Exp Med 177, 529-534.

[41] Cox, D., Tseng, C.C., Bjekic, G., and Greenberg, S. (1999). A requirement for phosphatidylinositol 3-kinase in pseudopod extension. J Biol Chem 274, 1240-1247.

[42] Lennartz, M.R., and Brown, E.J. (1991). Arachidonic acid is essential for IgG Fc receptormediated phagocytosis by human monocytes. J Immunol 147, 621-626.

[43] Debets, J.M., Van Der Linden, C.J., Dieteren, I.E., Leeuwenberg, J.F., and Buurman, W.A. (1988). Fc-receptor cross-linking induces rapid secretion of tumor necrosis factor (cachectin) by human peripheral blood monocytes. J Immunol 141, 1197-1201.

[44] Polat, G.L., Laufer, J., Fabian, I., and Passwell, J.H. (1993). Cross-linking of monocyte plasma membrane $\mathrm{Fc} \alpha, \mathrm{F} c \gamma$ or mannose receptors induces TNF production. Immunology 80, 287-292.

[45] Krutmann, J., Kirnbauer, R., Kock, A., Schwarz, T., Schopf, E., May, L.T., Sehgal, P.B., and Luger, T.A. (1990). Cross-linking FC receptors on monocytes triggers IL-6 production. Role in anti-CD3-induced T cell activation. J Immunol 145, 1337-1342.

[46] Marsh, C.B., Gadek, J.E., Kindt, G.C., Moore, S.A., and Wewers, M.D. (1995). Monocyte Fc $\gamma$ receptor cross-linking induces IL-8 production. J Immunol 155, 3161-3167.

[47] Marsh, C.B., Wewers, M.D., Tan, L.C., and Rovin, B.H. (1997). Fcy receptor cross-linking induces peripheral blood mononuclear cell monocyte chemoattractant protein-1 expression: role of lymphocyte FcyRIII. J Immunol 158, 1078-1084.

[48] Muroi, M., Muroi, Y., and Suzuki, T. (1994). The binding of immobilized IgG2a to Fc $\gamma 2 a$ receptor activates NF- $\mathrm{KB}$ via reactive oxygen intermediates and tumor necrosis factor$\alpha^{1}$. J Biol Chem 269, 30561-30568.

[49] Rose, D.M., Winston, B.W., Chan, E.D., Riches, D.W., Gerwins, P., Johnson, G.L., and Henson, P.M. (1997). Fc $\gamma$ receptor cross-linking activates p42, p38, and JNK/SAPK mitogen-activated protein kinases in murine macrophages: role for $\mathrm{p} 42^{\mathrm{MAPK}}$ in $\mathrm{Fc} \gamma$ receptor-stimulated TNF- $\alpha$ synthesis. J Immunol 158, 3433-3438.

[50] Ben-Sasson, S.Z., Le Gros, G., Conrad, D.H., Finkelman, F.D., and Paul, W.E. (1990). Cross-linking $F_{C}$ receptors stimulate splenic non-B, non- $T$ cells to secrete interleukin 4 and other lymphokines. Proc Natl Acad Sci U S A 87, 1421-1425.

[51] Gallo, P., Goncalves, R., and Mosser, D.M. (2010). The influence of IgG density and macrophage Fc (gamma) receptor cross-linking on phagocytosis and IL-10 production. Immunol Lett 133, 70-77.

[52] Ehlenberger, A.G., and Nussenzweig, V. (1977). The role of membrane receptors for C3b and C3d in phagocytosis. J Exp Med 145, 357-371. 
[53] Shi, Y., Tohyama, Y., Kadono, T., He, J., Miah, S.M., Hazama, R., Tanaka, C., Tohyama, K., and Yamamura, H. (2006). Protein-tyrosine kinase Syk is required for pathogen engulfment in complement-mediated phagocytosis. Blood 107, 4554-4562.

[54] Marth, T., and Kelsall, B.L. (1997). Regulation of interleukin-12 by complement receptor 3 signaling. J Exp Med 185, 1987-1995.

[55] Behrens, E.M., Sriram, U., Shivers, D.K., Gallucci, M., Ma, Z., Finkel, T.H., and Gallucci, S. (2007). Complement receptor 3 ligation of dendritic cells suppresses their stimulatory capacity. J Immunol 178, 6268-6279.

[56] Takahashi, K. (2001). Development and differentiation of macrophages and related cells: Historical review and current concepts. J Clin Exp Hematopathol 41, 1-33.

[57] Gordon, S. (2002). Pattern recognition receptors: doubling up for the innate immune response. Cell 111, 927-930.

[58] Pedra, J.H., Cassel, S.L., and Sutterwala, F.S. (2009). Sensing pathogens and danger signals by the inflammasome. Curr Opin Immunol 21, 10-16.

[59] Gough, P.J., and Gordon, S. (2000). The role of scavenger receptors in the innate immune system. Microbes Infect 2, 305-311.

[60] Haworth, R., Platt, N., Keshav, S., Hughes, D., Darley, E., Suzuki, H., Kurihara, Y., Kodama, T., and Gordon, S. (1997). The macrophage scavenger receptor type A is expressed by activated macrophages and protects the host against lethal endotoxic shock. J Exp Med 186, 1431-1439.

[61] Hamilton, R.F., Jr., Thakur, S.A., and Holian, A. (2008). Silica binding and toxicity in alveolar macrophages. Free Radic Biol Med 44, 1246-1258.

[62] Kobayashi, Y., Miyaji, C., Watanabe, H., Umezu, H., Hasegawa, G., Abo, T., Arakawa, M., Kamata, N., Suzuki, H., Kodama, T., et al. (2000). Role of macrophage scavenger receptor in endotoxin shock. J Pathol 192, 263-272.

[63] Baranova, I.N., Vishnyakova, T.G., Bocharov, A.V., Leelahavanichkul, A., Kurlander, R., Chen, Z., Souza, A.C., Yuen, P.S., Star, R.A., Csako, G., et al. (2012). Class B scavenger receptor types I and II and CD36 mediate bacterial recognition and proinflammatory signaling induced by Escherichia coli, lipopolysaccharide, and cytosolic chaperonin $60 . J$ Immunol 188, 1371-1380.

[64] Moestrup, S.K., and Moller, H.J. (2004). CD163: a regulated hemoglobin scavenger receptor with a role in the anti-inflammatory response. Ann Med 36, 347-354.

[65] Takeda, K., and Akira, S. (2005). Toll-like receptors in innate immunity. Int Immunol 17, $1-14$.

[66] Judge, A.D., Sood, V., Shaw, J.R., Fang, D., Mcclintock, K., and Maclachlan, I. (2005). Sequence-dependent stimulation of the mammalian innate immune response by synthetic siRNA. Nat Biotechnol 23, 457-462.

[67] Hornung, V., Guenthner-Biller, M., Bourquin, C., Ablasser, A., Schlee, M., Uematsu, S., Noronha, A., Manoharan, M., Akira, S., De Fougerolles, A., et al. (2005). Sequencespecific potent induction of IFN-alpha by short interfering RNA in plasmacytoid dendritic cells through TLR7. Nat Med 11, 263-270.

[68] Steinhagen, F., Kinjo, T., Bode, C., and Klinman, D.M. (2011). TLR-based immune adjuvants. Vaccine 29, 3341-3355. 
[69] Akita, H., Kogure, K., Moriguchi, R., Nakamura, Y., Higashi, T., Nakamura, T., Serada, S., Fujimoto, M., Naka, T., Futaki, S., et al. (2010). Nanoparticles for ex vivo siRNA delivery to dendritic cells for cancer vaccines: programmed endosomal escape and dissociation. J Control Release 143, 311-317.

[70] Pittella, F., Zhang, M., Lee, Y., Kim, H.J., Tockary, T., Osada, K., Ishii, T., Miyata, K., Nishiyama, N., and Kataoka, K. (2011). Enhanced endosomal escape of siRNAincorporating hybrid nanoparticles from calcium phosphate and PEG-block chargeconversional polymer for efficient gene knockdown with negligible cytotoxicity. Biomaterials 32, 3106-3114.

[71] Agostini, L., Martinon, F., Burns, K., Mcdermott, M.F., Hawkins, P.N., and Tschopp, J. (2004). NALP3 forms an IL-1beta-processing inflammasome with increased activity in Muckle-Wells autoinflammatory disorder. Immunity 20, 319-325.

[72] Cassel, S.L., Joly, S., and Sutterwala, F.S. (2009). The NLRP3 inflammasome: a sensor of immune danger signals. Semin Immunol 21, 194-198.

[73] Hornung, V., Bauernfeind, F., Halle, A., Samstad, E.O., Kono, H., Rock, K.L., Fitzgerald, K.A., and Latz, E. (2008). Silica crystals and aluminum salts activate the NALP3 inflammasome through phagosomal destabilization. Nat Immunol 9, 847-856.

[74] Halle, A., Hornung, V., Petzold, G.C., Stewart, C.R., Monks, B.G., Reinheckel, T., Fitzgerald, K.A., Latz, E., Moore, K.J., and Golenbock, D.T. (2008). The NALP3 inflammasome is involved in the innate immune response to amyloid-beta. Nat Immunol 9, 857-865.

[75] Simons, K., and Ikonen, E. (1997). Functional rafts in cell membranes. Nature 387, 569572.

[76] Simons, K., and Toomre, D. (2000). Lipid rafts and signal transduction. Nat Rev Mol Cell Biol 1, 31-39.

[77] Kim, H.Y., Park, S.J., Joe, E.H., and Jou, I. (2006). Raft-mediated Src homology 2 domain-containing protein tyrosine phosphatase 2 (SHP-2) regulation in microglia. $J$ Biol Chem 281, 11872-11878.

[78] Hoekstra, D., Maier, O., Van Der Wouden, J.M., Slimane, T.A., and Van, I.S.C. (2003). Membrane dynamics and cell polarity: the role of sphingolipids. J Lipid Res 44, 869-877.

[79] Zhang, J., Pekosz, A., and Lamb, R.A. (2000). Influenza virus assembly and lipid raft microdomains: a role for the cytoplasmic tails of the spike glycoproteins. J Virol 74, 4634-4644.

[80] Thorne, R.F., Marshall, J.F., Shafren, D.R., Gibson, P.G., Hart, I.R., and Burns, G.F. (2000). The integrins $\alpha_{3} \beta_{1}$ and $\alpha_{6} \beta_{1}$ physically and functionally associate with CD36 in human melanoma cells - Requirement for the extracellular domain of CD36. J Biol Chem 275, 35264-35275.

[81] Rodal, S.K., Skretting, G., Garred, O., Vilhardt, F., Van Deurs, B., and Sandvig, K. (1999). Extraction of cholesterol with methyl- $\beta$-cyclodextrin perturbs formation of clathrincoated endocytic vesicles. Mol Biol Cell 10, 961-974.

[82] Nagao, G., Ishii, K., Hirota, K., Makino, K., and Terada, H. (2010). Role of lipid rafts in phagocytic uptake of polystyrene latex microspheres by macrophages. Anticancer Res. 30, 3167-3176.

[83] Persaud-Sawin, D.A., Banach, L., and Harry, G.J. (2009). Raft aggregation with specific receptor recruitment is required for microglial phagocytosis of Abeta42. Glia 57, 320-335. 
[84] Pfeiffer, A., Bottcher, A., Orso, E., Kapinsky, M., Nagy, P., Bodnar, A., Spreitzer, I., Liebisch, G., Drobnik, W., Gempel, K., et al. (2001). Lipopolysaccharide and ceramide docking to CD14 provokes ligand-specific receptor clustering in rafts. Eur J Immunol 31, 3153-3164.

[85] Kariko, K., Weissman, D., and Welsh, F.A. (2004). Inhibition of toll-like receptor and cytokine signaling--a unifying theme in ischemic tolerance. J Cereb Blood Flow Metab 24, 1288-1304.

[86] Dai, Q., and Pruett, S.B. (2006). Ethanol suppresses LPS-induced Toll-like receptor 4 clustering, reorganization of the actin cytoskeleton, and associated TNF- $\alpha$ production. Alcohol Clin Exp Res 30, 1436-1444.

[87] Nagao, G., Ishii, K., Hirota, K., Makino, K., and Terada, H. (2011). Role of lipid rafts in innate immunity and phagocytosis of polystyrene latex microspheres. Colloid Surf B: Biointerfaces 84, 317-324.

[88] Olsson, S., and Sundler, R. (2006). The role of lipid rafts in LPS-induced signaling in a macrophage cell line. Mol Immunol 43, 607-612.

[89] O'hara, P., and Hickey, A.J. (2000). Respirable PLGA microspheres containing rifampicin for the treatment of tuberculosis: manufacture and characterization. Pharm Res 17, 955-961.

[90] Sharma, R., Saxena, D., Dwivedi, A.K., and Misra, A. (2001). Inhalable microparticles containing drug combinations to target alveolar macrophages for treatment of pulmonary tuberculosis. Pharm Res 18, 1405-1410.

[91] Verma, R.K., Kaur, J., Kumar, K., Yadav, A.B., and Misra, A. (2008). Intracellular time course, pharmacokinetics, and biodistribution of isoniazid and rifabutin following pulmonary delivery of inhalable microparticles to mice. Antimicrob Agents Chemother 52, 3195-3201.

[92] Yoshida, A., Matumoto, M., Hshizume, H., Oba, Y., Tomishige, T., Inagawa, H., Kohchi, C., Hino, M., Ito, F., Tomoda, K., et al. (2006). Selective delivery of rifampicin incorporated into poly(DL-lactic-co-glycolic) acid microspheres after phagocytotic uptake by alveolar macrophages, and the killing effect against intracellular Mycobacterium bovis Calmette-Guerin. Microbes Infect 8, 2484-2491.

[93] Taniguchi, H., Shimada, Y., Sawachi, K., Hirota, K., Inagawa, H., Kohchi, C., Soma, G., Makino, K., and Terada, H. (2010). Lipopolysaccharide-activated alveolar macrophages having cytotoxicity toward lung tumor cells through cell-to-cell binding-dependent mechanism. Anticancer Res 30, 3159-3165.

[94] Sawachi, K., Shimada, Y., Taniguchi, H., Hirota, K., Inagawa, H., Kohchi, C., Soma, G., Makino, K., and Terada, H. (2010). Cytotoxic effects of activated alveolar macrophages on lung carcinoma cells via cell-to-cell contact and nitric oxide. Anticancer Res 30, 3135-3141.

[95] Hirota, K., Oishi, Y., Taniguchi, H., Sawachi, K., Inagawa, H., Kohchi, C., Soma, G., and Terada, H. (2010b). Antitumor effect of inhalatory lipopolysaccharide and synergetic effect in combination with cyclophosphamide. Anticancer Res 30, 3129-3134.

[96] Hagemann, T., Lawrence, T., Mcneish, I., Charles, K.A., Kulbe, H., Thompson, R.G., Robinson, S.C., and Balkwill, F.R. (2008). "Re-educating" tumor-associated macrophages by targeting NF- $\kappa$ B. J Exp Med 205, 1261-1268. 